\title{
Galantamine Enhances Dopaminergic Neurotransmission In Vivo Via Allosteric Potentiation of Nicotinic Acetylcholine Receptors
}

\author{
Björn Schilström*,', Vladimir B Ivanov', Charlotte Wiker' and Torgny H Svensson' \\ 'Section of Neuropsychopharmacology, Department of Physiology and Pharmacology, Karolinska Institutet, Stockholm, Sweden
}

\begin{abstract}
Clinical studies suggest that adjunct galantamine may improve negative and cognitive symptoms in schizophrenia. These symptoms may be related to impaired dopaminergic function in the prefrontal cortex. Indeed, galantamine has been shown to increase dopamine release in vitro. Galantamine is an allosteric modulator of nicotinic acetylcholine receptors (nAChRs) and, at higher doses, an acetylcholine esterase (AChE) inhibitor. We have previously shown that nicotine, through stimulation of nAChRs in the ventral tegmental area (VTA), activates midbrain dopamine neurons and, hence, potentiation of these receptors could be an additional mechanism by which galantamine can activate dopaminergic pathways. Therefore, the effects of galantamine (0.0 I-1.0 mg/ $/ \mathrm{kg}$ s.c.) on dopamine cell firing were tested in anaesthetized rats. Already at a low dose, unlikely to result in significant AchE inhibition, galantamine increased firing activity of dopaminergic cells in the VTA. The effect of galantamine was prevented by the nAChR antagonist mecamylamine (1.0 mg/kg s.c.), but not the muscarinic receptor antagonist scopolamine (0.1 mg/kg s.c.), and it was not mimicked by the selective AChE inhibitor donepezil $(1.0 \mathrm{mg} / \mathrm{kg}$ s.c.). Our data thus indicate that galantamine increases dopaminergic activity through allosteric potentiation of $\mathrm{nAChRs}$. Galantamine's effect was also prevented by the $\alpha 7$ nAChR antagonist methyllycaconitine $(6.0 \mathrm{mg} / \mathrm{kg}$ i.p.) as well as the N-methyl-Daspartate antagonist CGP3955 I (2.5 mg/kg s.c.), indicating a mechanism involving presynaptic facilitation of glutamate release. In parallel microdialysis experiments, galantamine was found to increase extracellular levels of dopamine in the medial prefrontal cortex. These results may have bearing on the enhancement of negative and cognitive symptoms in schizophrenia.

Neuropsychopharmacology (2007) 32, 43-53. doi:I 0. I038/sj.npp. I 301087; published online 26 April 2006
\end{abstract}

Keywords: ventral tegmental area; schizophrenia; prefrontal; cognitive; NMDA

\section{INTRODUCTION}

The acetylcholine esterase ( $\mathrm{AChE}$ ) inhibitor galantamine is currently used for symptomatic treatment of Alzheimer's disease, the pathophysiology of which involves degeneration of cholinergic neurons (Davies and Maloney, 1976). Recent clinical data suggest that galantamine might also be useful as adjunct therapy in schizophrenia, as it has been found to improve both negative and cognitive symptoms of the disease (Rosse and Deutsch, 2002; Allen and McEvoy, 2002; Bora et al, 2005). It has been hypothesized that increasing cholinergic neurotransmission in the cortex may be a generally desirable effect of antipsychotic drugs since those that are most effective against cognitive symptoms also increases the extracellular levels of cortical acetylcholine (Ichikawa et al, 2002). However, clinical data

\footnotetext{
*Correspondence: Dr B Schilström, Section of Neuropsychopharmacology, Department of Physiology and Pharmacology, Karolinska Institutet, 171 77 Stockholm, Sweden, Tel: + 4685248 7916, Fax: + 468 308424, E-mail: bjorn.schilstrom@fyfa.ki.se

Received 23 January 2006; revised 7 March 2006; accepted 16 March 2006

Online publication: 23 March 2006 at http://www.acnp.org/citations/ Npp032306060043/default.pdf
}

suggest that while the weak AChE inhibitor galantamine has beneficial effects in schizophrenia, the more potent and specific AChE donepezil has not (Friedman et al, 2003). These studies suggest that a mechanism separate from acetylcholine esterase inhibition may be involved in the effect of galantamine on schizophrenia. In fact, galantamine has two separate mechanisms of action which can both enhance cholinergic neurotransmission in the brain. At low doses, it binds allosterically to nicotinic acetylcholine receptors (nAChRs) and potentiates their function, and at high doses it acts as a weak AChE inhibitor (Schrattenholz et al, 1996; Maelicke et al, 2000). Thus, while selective AChE inhibitors may increase cholinergic neurotransmission at both muscarinic acetylcholine receptors (mAChRs) and nAChRs, galantamine has the potential of preferentially potentiating endogenous cholinergic neurotransmission occurring at nAChRs and this difference may explain the drugs' differing clinical profile.

Both clinical and preclinical studies suggest that negative and cognitive symptoms in schizophrenia may involve dysfunctional dopaminergic neurotransmission in the prefrontal cortex (for a recent review, see Svensson, 2003). Among the cognitive deficits reliably observed in schizophrenic patients are impairments in working memory, that 
is, an impaired ability to retain and manipulate information over a short period of time. Working memory is largely executed in various regions of the prefrontal cortex and depends on an accurate level of dopamine D1 receptor stimulation (Arnsten et al, 1994). A recent PET study in schizophrenic patients reported increased dopamine D1 receptor availability in the prefrontal cortex (Abi-Dargham et al, 2002). Furthermore, a negative correlation between the D1 receptor availability and performance on a task requiring working memory was observed. Based on these findings it was suggested that dopamine D1 receptors are upregulated to compensate for decreased release of dopamine. Thus, a dopamine-dependent working memory deficit in schizophrenia is not likely due to a dopamine deficiency at the receptor level, but rather to upstream mechanisms that control the release or degradation of dopamine (Egan et al, 2001).

Recently, galantamine was shown to increase nerve terminal release of dopamine in vitro (Zhang et al, 2004), but because of the in vitro preparation used any action of galantamine within the dopaminergic cell body region could not be detected. However, earlier data from our laboratory has shown that nicotine activates dopamine cell firing rate as well as burst firing (Grenhoff et al, 1986) and that nAChRs in the ventral tegmental area (VTA) are critically involved in nicotine's stimulatory effect on terminal dopamine release (Nisell et al, 1994; Schilström et al, 1998b). Specifically, burst firing induced by nicotine is in all probability due to presynaptic enhancement of afferent glutamate release. Nicotine has been shown to activate presynaptic $\alpha 7$-subunit containing nAChRs in the VTA and enhance glutamate release that leads to stimulation of $N$ methyl-D-aspartate (NMDA) receptors on dopamine cells (Schilström et al, 1998a, b, 2000; Mansvelder and McGehee, 2000; Schilström et al, 2003). Moreover, heteromeric $\beta 2$ containing nAChRs on dopamine cell bodies and $\gamma$-aminobyturic acid (GABA)-ergic interneurons also influence the activity of dopaminergic neurons (Calabresi et al, 1989; Picciotto et al, 1998; Mansvelder et al, 2002; Schilström et al, 2003). These studies indirectly suggest additional mechanisms by which galantamine can improve negative and cognitive symptoms in schizophrenia. Thus, through its action as an allosteric modulator of nAChRs, galantamine may, accordingly, facilitate dopamine release by increasing dopaminergic firing through potentiation of $\mathrm{nAChR}$ function in the VTA. Therefore, using in vivo single unit recordings, we investigated the effect of galantamine on dopamine cell firing. Galantamine's effect was analyzed pharmacologically using the subtype nonselective nAChR antagonist mecamylamine, the $\mathrm{mAChR}$ antagonist scopolamine, the selective AChE inhibitor donepezil as well as the $\alpha 7$-selective $\mathrm{nAChR}$ antagonist methyllycaconitine (MLA), and the NMDA receptor antagonist CGP39551. Moreover, using in vivo microdialysis, the effect of galantamine on dopamine output in the prefrontal cortex was examined.

\section{MATERIALS AND METHODS}

All experiments were approved by, and conducted in accordance with, the Stockholm North Committee on
Ethics of Animal Experimentation (ethical approval numbers N18/01, N18/04, and N340/02). Efforts were made to minimize the number of animals used and their suffering.

\section{Extracellular Single Cell Recording of Dopaminergic Neurons of the VTA In Vivo}

The procedures for extracellular single cell recording have been described previously (Grenhoff et al, 1986; Schilström et al, 2003). Rats (250-300 g; male Sprague-Dawley, BK Universal, Sollentuna, Sweden) were anaesthetized with chloral hydrate $(400 \mathrm{mg} / \mathrm{kg}$ i.p.) and mounted in a stereotaxic frame (David Kopf, Tujunga, CA). Anesthesia was maintained throughout the experiment with periodical injections of chloral hydrate (approximately $150 \mathrm{mg} / \mathrm{kg} / \mathrm{h}$ i.p.) and body temperature was kept at $37^{\circ} \mathrm{C}$ with a rectal thermometer connected to an electrical heating pad. Recording electrodes were pulled in a Narishige (Tokyo, Japan) vertical puller from borosilicate glass capillaries (Clark Electromedical Instruments, Reading, UK) with outer and inner diameters of 1.50 and $1.17 \mathrm{~mm}$, respectively, and filled with $2 \%$ Pontamine Sky Blue in $2 \mathrm{M} \mathrm{NaCl}$. The tips of the electrodes were broken to yield an impedance of 2-4 M $\Omega$ at $135 \mathrm{~Hz}$ and then slowly lowered into a hole drilled in the skull above the VTA $(3.2 \pm 0.3 \mathrm{~mm}$ anterior of the interaural line and $0.7 \pm 0.2 \mathrm{~mm}$ lateral to the midline; Paxinos and Watson, 1998) by using a hydraulic microdrive (David Kopf, Tujunga, CA). Presumed dopamine neurons were found $7.5-8.5 \mathrm{~mm}$ from the brain surface and were recognized by their characteristic triphasic action potential waveform of more than $2.0 \mathrm{~ms}$ duration, basal firing rates of $1-10 \mathrm{~Hz}$, and frequent occurrence of burst firing (Wang, 1981). Moreover, the 'Ungless-filter', consisting of tail- or toe-pinch, was applied and only cells that responded with a transient inhibition of firing were included in the study (Ungless et al, 2004). Extracellular electrical activity was amplified, filtered (band pass $0.3-3 \mathrm{kHz}$ ), discriminated, and monitored on an oscilloscope (TDS 310, Tektronix, Beaverton, OR) and an audiomonitor (Grass, AM8B/C, West Warwick, RI). Discriminated spikes were fed via a CED 1401 interface (Cambridge Electronic Design, Ltd, Cambridge, UK) to a computer running CED Spike 2 software. After completion of the experiment, the position of the electrode was marked by iontophoresis of Pontamine Sky Blue into the tissue $(5 \mu \mathrm{A}$ for $5 \mathrm{~min})$. The rat was killed with an overdose of anesthetic, and the brain was removed and placed in $25 \%$ sucrose, $10 \%$ paraformaldehyde solution. Sections of the VTA were cut $(50 \mu \mathrm{M})$ and stained with neutral red and the recording sites were verified by light microscopy.

\section{Microdialysis}

Rats (male Wistar, BK Universal, Sollentuna, Sweden) were anaesthetized with a cocktail containing Hypnorm ${ }^{\circledR}$ (Fentanyl $0.315 \mathrm{mg} / \mathrm{ml}+$ Fluanison $10 \mathrm{mg} / \mathrm{ml}$, Janssen-Cilag) and Dormicum $^{\circledR}$ (Midazolam $5 \mathrm{mg} / \mathrm{ml}$, Roche) diluted in distilled water $(1: 1: 2 ; 5 \mathrm{ml} / \mathrm{kg}$ i.p.) and mounted in a stereotaxic frame. Dialysis probes were implanted in the medial PFC (AP: + 3.0:ML $\pm 0.6: \mathrm{DV}:-5.2$, relative to bregma and the dural surface according to the atlas of 
Paxinos and Watson, 1998). Dialysis occurred through a semipermeable membrane (Filtral AN69, Hospal Industrie, France) with an active surface length of $4 \mathrm{~mm}$. Dialysis experiments were conducted approximately $48 \mathrm{~h}$ after surgery in freely moving rats. The dialysis probe was perfused with a physiological perfusion solution (Apoteksbolaget, Sweden) at a rate of $2.5 \mu \mathrm{l} / \mathrm{min}$ set by a microinfusion pump (Harvard Apparatus, Holliston, MA). Dialysate was collected over $30 \mathrm{~min}$ intervals and automatically injected into a high-performance liquid chromatography system. On-line quantification of dopamine in the dialysate was accomplished by electrochemical detection (ESA, Chelmsford, MA). Following experiment, the rat was killed with an overdose of anesthetic, the brain was removed and placed in $25 \%$ sucrose, $10 \%$ paraformaldehyde solution. Sections of the VTA were cut $(50 \mu \mathrm{M})$ and stained with neutral red and the probe placements sites were verified by light microscopy.

\section{Drugs}

Galantamine and donepezil were generously provided by Janssen Cilag AB, and CGP39551 was a generous gift from Novartis. Scopolamine, mecamylamine, and MLA were purchased from the local Sigma-Aldrich supplier (Stockholm, Sweden). All drugs were dissolved in physiological saline solution and, besides MLA, which was injected intraperitoneally, drugs were injected subcutaneously. In electrophysiological experiments, when applicable, drugs were administered approximately $10 \mathrm{~min}$ apart.

\section{Data Analysis}

Electrophysiology. Dopamine cell firing was analyzed with respect to the average firing rate and the percentage of action potentials fired in bursts, calculated over consecutive periods of 500 inter-spike time intervals (ISI). Since the time period during which spikes are analyzed will depend on firing frequency, in cells with firing frequencies lower than $3.0 \mathrm{~Hz}$, consecutive periods of 250 ISI intervals were used to yield better time resolution. In experiments in which only one drug was administered, the last analyzed period before drug injection was compared to the period within 15 min after injection representing the median effect. In experiments in which two drugs were administered, the last period before any drug injection was compared to the median effect observed within $15 \mathrm{~min}$ of injection of galantamine (or donepezil). Firing rate data were statistically analyzed with two-way analysis of variance (ANOVA) followed by Newman-Keul's test for multiple comparisons or Student's paired $t$-test when appropriate. Values for all the individual cells are presented in figures with lines indicating mean \pm SEM. Analysis of burst firing was performed on the percentage of spikes fired in bursts in the last analyzed period before injection and was compared to the period within $15 \mathrm{~min}$ after injection representing the median effect. Burst firing is defined as a series of spikes starting when the interval between two spikes is lower than $80 \mathrm{~ms}$ and terminating when the interval exceeds $160 \mathrm{~ms}$ (Grace and Bunney, 1984). Since burst firing was not normally distributed, the nonparametric Kruskal-Wallis
ANOVA or the Mann-Whitney $U$-test was used to analyze differences between treatments and Wilcoxon matched pairs signed ranks test was used to evaluate within effects of the different treatments. Data are presented in figures as absolute pre- and postinjection values for all the individual cells and the median across cells is indicated with a horizontal line.

Microdialysis. Dopamine levels were expressed and statistically analyzed as percent of basal levels. Baseline was defined as the average of the two samples immediately preceding treatment. The mean percent changes were then calculated for each 30 min sample or all rats in each group. Three experimental groups were included. The effect of galantamine on dopamine output in the prefrontal cortex was tested at 0.1 and $1.0 \mathrm{mg} / \mathrm{kg}$ s.c and to control for injection effects a vehicle group was included. Data were analyzed by one- and two-way (treatment $\times$ time) ANOVA with repeated measures followed by the Newman-Keuls test for multiple comparisons. All statistical analyses were performed using the STATISTICA software (Statsoft, Inc., Tulsa, OK, USA).

\section{RESULTS}

\section{Effects of Galantamine on Dopamine Cell Firing}

Galantamine was tested in the doses $0.01,0.1$, and $1.0 \mathrm{mg} / \mathrm{kg}$ s.c. (Figure 1). Two-way ANOVA analysis of the firing rate data revealed a significant time $\left(\mathrm{F}_{1,25}=16.114, p<0.001\right)$, but not a group or interaction effect. Further statistical analysis showed that the mean firing rate increases from $4.61 \pm 0.71 \mathrm{~Hz}$ under baseline conditions to $4.90 \pm 0.68 \mathrm{~Hz}$ following injection of $0.01 \mathrm{mg} / \mathrm{kg}$ (s.c.) galantamine $(p<0.05$, Figure $1 \mathrm{~b})$ and from $5.51 \pm 0.58 \mathrm{~Hz}$ to $5.95 \pm$ $0.52 \mathrm{~Hz}$ following $0.1 \mathrm{mg} / \mathrm{kg}$ (s.c.) galantamine $(p<0.01$, Figure $1 \mathrm{a}$ and $\mathrm{b}$ ) were significant, but the slight elevation from $5.36 \pm 0.53 \mathrm{~Hz}$ to $5.55 \pm 0.46 \mathrm{~Hz}$ following $1.0 \mathrm{mg} / \mathrm{kg}$ (s.c.) galantamine was not ( $p>0.05$, Figure 1b). Burst firing is a variable that tends not to follow a normal distribution. Descriptive statistics revealed that this was the case also in our experiments (skewness $<-1$ or skewness $>1$ ) and therefore the results were analyzed by Kruskal-Wallis ANOVA and Wilcoxon's matched pairs signed ranks test. There were no significant differences between the groups before or after galantamine injection but all doses increased burst firing when compared to its own baseline. At $0.01 \mathrm{mg} /$ $\mathrm{kg}$, galantamine increased median burst firing from 7.2 to $10.8 \%(p<0.05, n=10$, Figure $1 \mathrm{c})$, at $0.1 \mathrm{mg} / \mathrm{kg}$ median burst firing increased from 24.4 to $46.3 \%(p<0.01, n=9$, Figure $1 \mathrm{a}$ and $\mathrm{b}$ ), and at $1.0 \mathrm{mg} / \mathrm{kg}$ galantamine the median burst firing increased from 4.4 to $27.2 \%(p<0.05, n=9$, Figure 1c). Since galantamine activates dopamine cells already at low doses that have been shown to result in very low AChE inhibition (Geerts et al, 2005), the present data suggest that the mechanism by which galantamine increases dopamine cell firing may be allosteric potentiation of nAChRs. Galantamine was most effective at activating dopaminergic cells at $0.1 \mathrm{mg} / \mathrm{kg}$ s.c. Therefore, our pharmacological characterization of galantamine's effect was performed using this dose. 

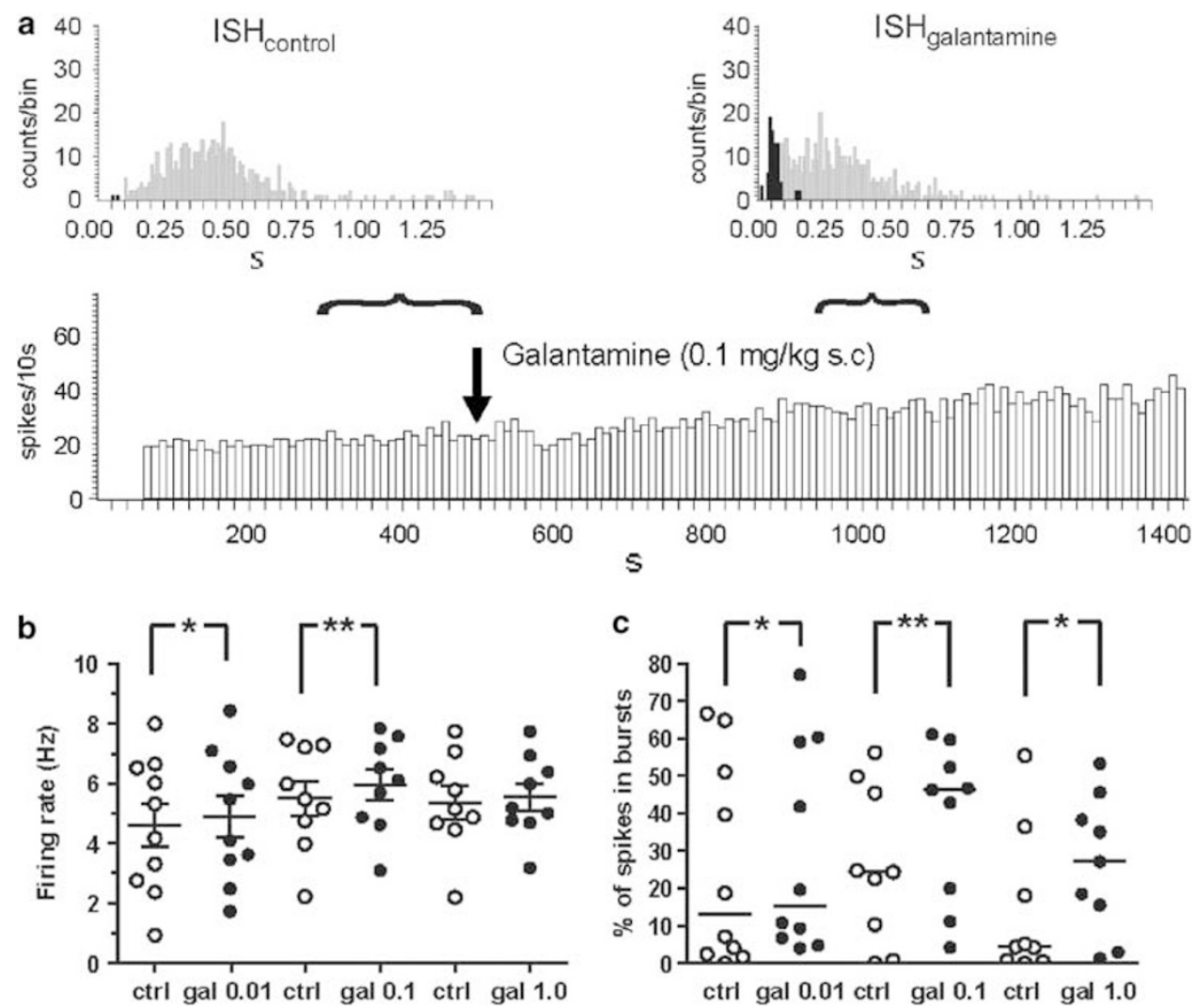

Figure I (a) Ratemeter recording and interspike time interval histograms (ISHs) of a representative experiment showing the effects of galantamine $(0.1 \mathrm{mg} / \mathrm{kg}$ s.c.) on firing rate and the percentage of spikes fired in bursts (as indicated by black bars in ISHs). Arrow indicates the time of injection. The time periods from which the spike analyses were performed are indicated above the ratemeter recording with lying curly brackets. (b) Summary graph showing the effects of varying doses of galantamine on firing rate. The firing rate for each cell is represented by an open circle (ctrl) before and a filled circle after galantamine injection. Horizontal lines indicate mean \pm SEM. (c) Summary graph showing the effects of varying doses of galantamine on burst firing. Each cell recorded is represented by an open circle before and a filled circle after galantamine injection. Horizontal line indicates the median. $*=p<0.05$, *** $=p<0.0 \mathrm{l}, \mathrm{ctrl}=$ control, gal $=$ galantamine

\section{Galantamine Activates Dopamine Cell Firing Via Activation of nAChRs}

If the effect of galantamine is due to inhibition of AChE, it would increase acetylcholine levels that could activate both nAChRs and mAChRs. Therefore, the effect of galantamine was tested in the presence of an antagonist at nAChRs and mAChRs, respectively. Thus, we first established a dose of the $\mathrm{nAChR}$ antagonist mecamylamine and the mAChR antagonist scopolamine that by themselves had no effect. Mecamylamine, when given at $1.0 \mathrm{mg} / \mathrm{kg}$ (s.c.), a dose that we have previously used to precipitate nicotine-withdrawal in chronically nicotine-treated rats (Hildebrand et al, 1998), produced no effects on firing activity of dopamine neurons. The frequency was $4.76 \pm 0.74 \mathrm{~Hz}$ before and $4.68 \pm 0.78$ after injection (paired $t$-test, $p>0.05, n=8$, data not shown). Burst firing was unchanged from $2.2 \%$ before and $6.6 \%$ after injection ( $p>0.05, n=8$, Wilcoxon's matched pairs signed ranks test). Scopolamine was first tested at $1.0 \mathrm{mg} / \mathrm{kg}$ s.c., but this dose clearly decreased firing rate (for this reason, experiments were not pursued to an $n$ high enough for statistical analysis, data not shown) and a lower dose was chosen. When given at $0.1 \mathrm{mg} / \mathrm{kg}$, scopolamine had no effect on firing activity. Basal firing rate was $5.34 \pm 0.76 \mathrm{~Hz}$ before and $5.15 \pm 0.75$ after scopol amine injection (paired $t$-test, $p>0.05, n=7$, data not shown). Numerically, median burst firing increased from 2.2 to $9.5 \%$, but since there was large variation the effect was not statistically significant $(p>0.05, n=7$, data not shown).

Two-way ANOVA comparing the effects of galantamine $(0.1 \mathrm{mg} / \mathrm{kg})$ in pretreated $v s$ nonpretreated animals revealed that there were no significant differences between the various groups, but there were time and interaction effects (F(interaction) $\left.)_{4,40}=3.628, p<0.05\right)$. Post hoc analysis revealed that although galantamine produced a significant effect in nonpretreated animals, it did not in mecamylamine-pretreated animals (basal $4.73 \pm 0.40 \mathrm{~Hz}$, postinjection $4.58 \pm 0.40 \mathrm{~Hz}, p>0.05, n=6$, Figure $2 \mathrm{a}$ and b). Moreover, in mecamylamine-pretreated rats, galantamine did not increase burst firing significantly (basal burst firing was $2.9 \%$ and post-galantamine injection $3.8 \%$, $p>0.05, n=6$, Figure $2 \mathrm{a}$ and c). In rats pretreated with scopolamine, galantamine increased firing rate in a majority of the nine cells tested $(5.30 \pm 0.61 \mathrm{~Hz}$ before and $5.93 \pm 0.60 \mathrm{~Hz}$ after injection, $p<0.001$, Figure $2 \mathrm{~b}$ and $\mathrm{d}$ ) and also burst firing increased in response to galantamine (from the basal value 28.7 to $51.1 \%$ postinjection, $p<0.05$, Figure $2 \mathrm{c}$ and $\mathrm{d}$ ). These data suggest that nAChRs, but not mAChRs, mediate the stimulatory effect of galantamine on 


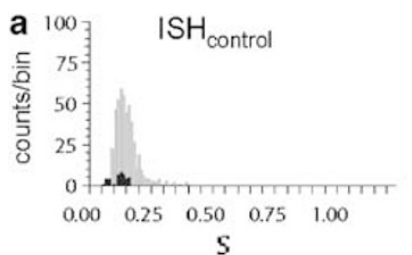

ISH $\mathrm{H}_{\text {control }}$
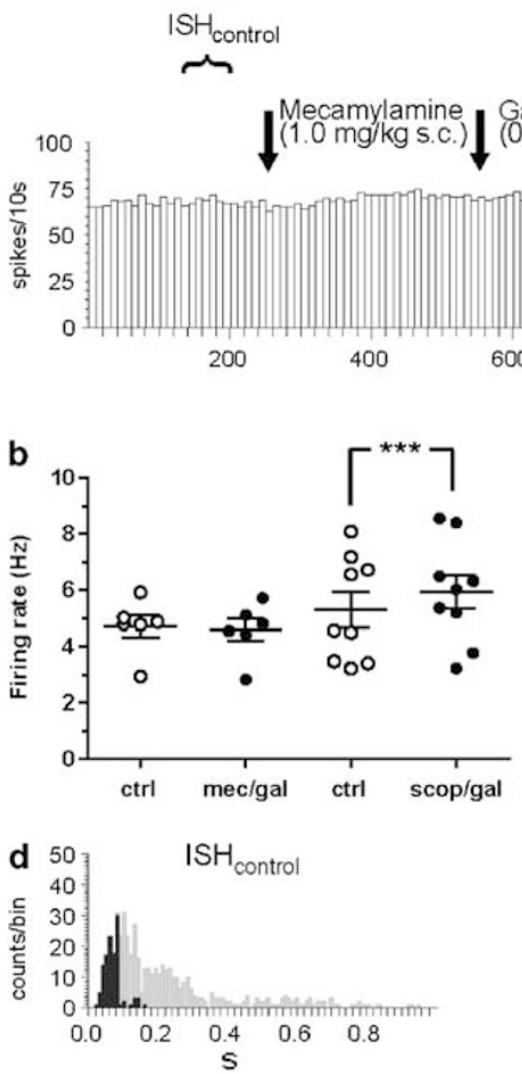

ISH $\mathrm{H}_{\text {control }}$
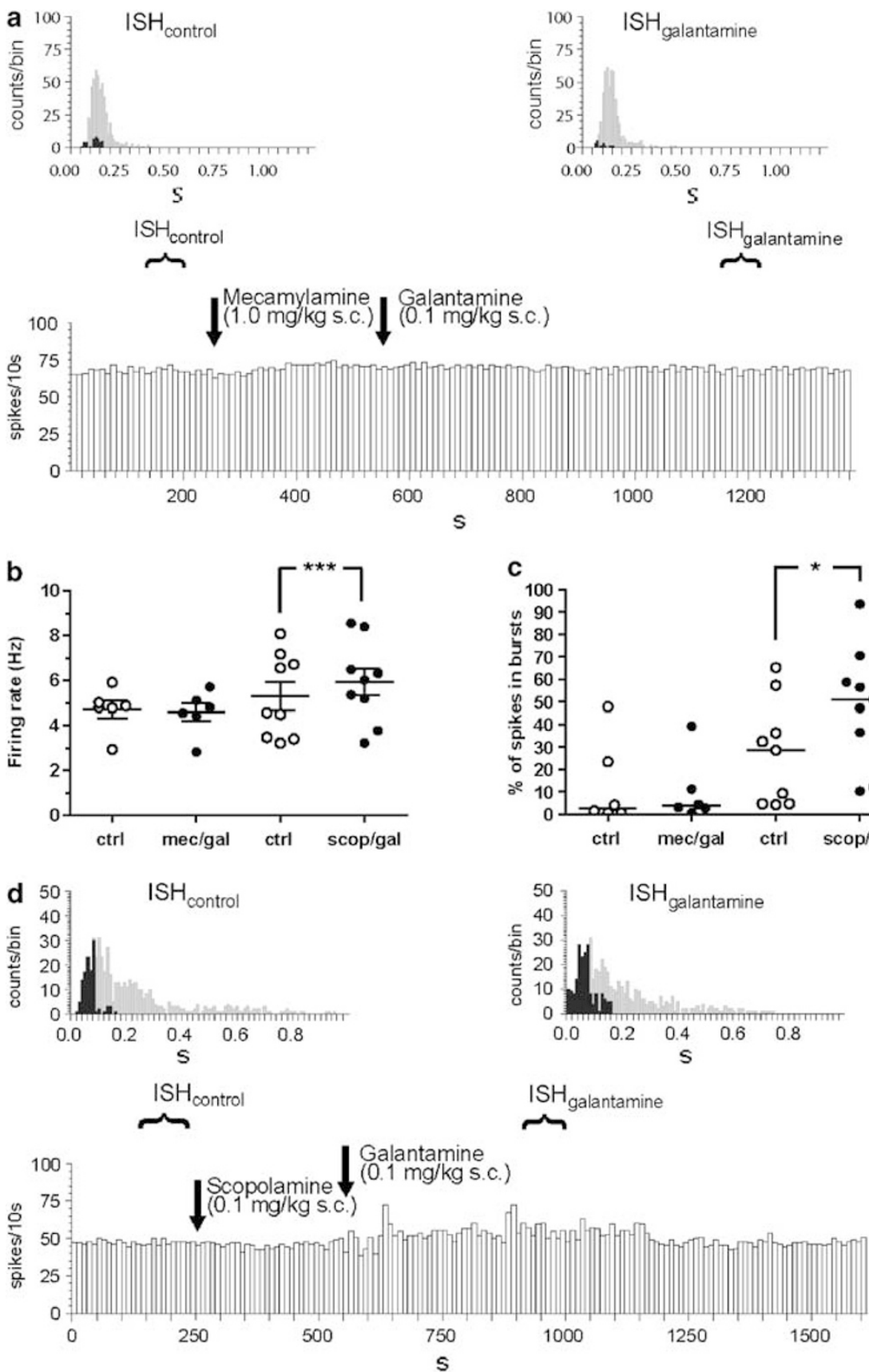

$800 \quad 1000 \quad 1200$

S
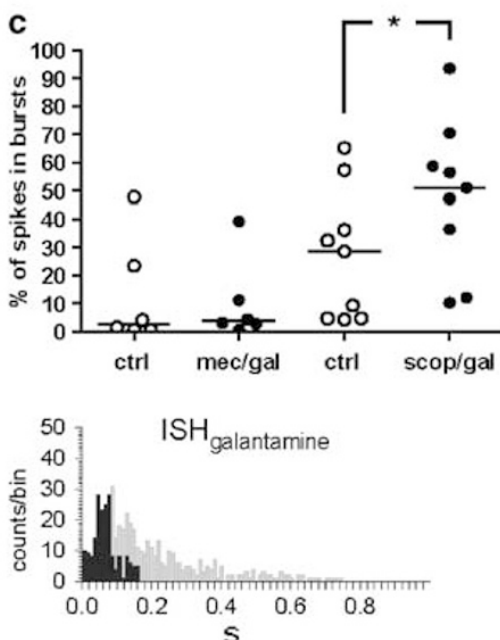

$\mathrm{ISH}_{\text {galantamine }}$

Figure 2 (a and d) Ratemeter recordings and ISHs showing the effects of (a) galantamine in the presence of the nAChR antagonist mecamylamine $(1.0 \mathrm{mg} / \mathrm{kg}$ s.c.) and (d) galantamine in the presence of the muscarinic receptor antagonist scopolamine. Arrows indicate the time of injections. The time periods from which the spike analyses were performed are indicated above the ratemeter recording with lying curly brackets. Effects of galantamine on firing rate in mecamylamine and scopolamine-pretreated animals are summarized in (b) in which the basal level (ctrl) for each cell is represented by an open circle and the effect of galantamine by a filled circle. Mean \pm SEM are indicated by horizontal lines. (c) Summary graph showing the effects on burst firing. Basal burst firing for each cell (ctrl) is indicated by an open circle and the effect of galantamine by a filled circle. Horizontal line indicates the median. gal = galantamine, $\mathrm{mec}=$ mecamylamine, scop $=$ scopolamine, $*=p<0.05, * * * *=0.00 \mathrm{I}$.

dopamine cell firing. Previous in vitro experiments have suggested that the long-lasting excitatory effects of nicotine on dopaminergic cells may be due to nicotine-induced synaptic plasticity (Mansvelder and McGehee, 2000). In order to test whether the effects of galantamine are reversible, we performed a separate set of experiments in which galantamine was administered first and then followed 5-10 min later by mecamylamine. Although mecamylamine was not able to reduce firing rate in naïve animals, administration of mecamylamine to galantamine-treated rats decreased firing rate of dopaminergic neurons from $4.76 \pm 0.76 \mathrm{~Hz}$ to $4.08 \pm 0.80 \mathrm{~Hz}(p<0.05, n=6$, paired $t$-test, data not shown). Moreover, mecamylamine reduced median burst firing in galantamine-treated rats from 36.8 to $13.7 \%$ $(p<0.05, n=6$, Wilcoxon's matched pairs signed ranks test, data not shown). 

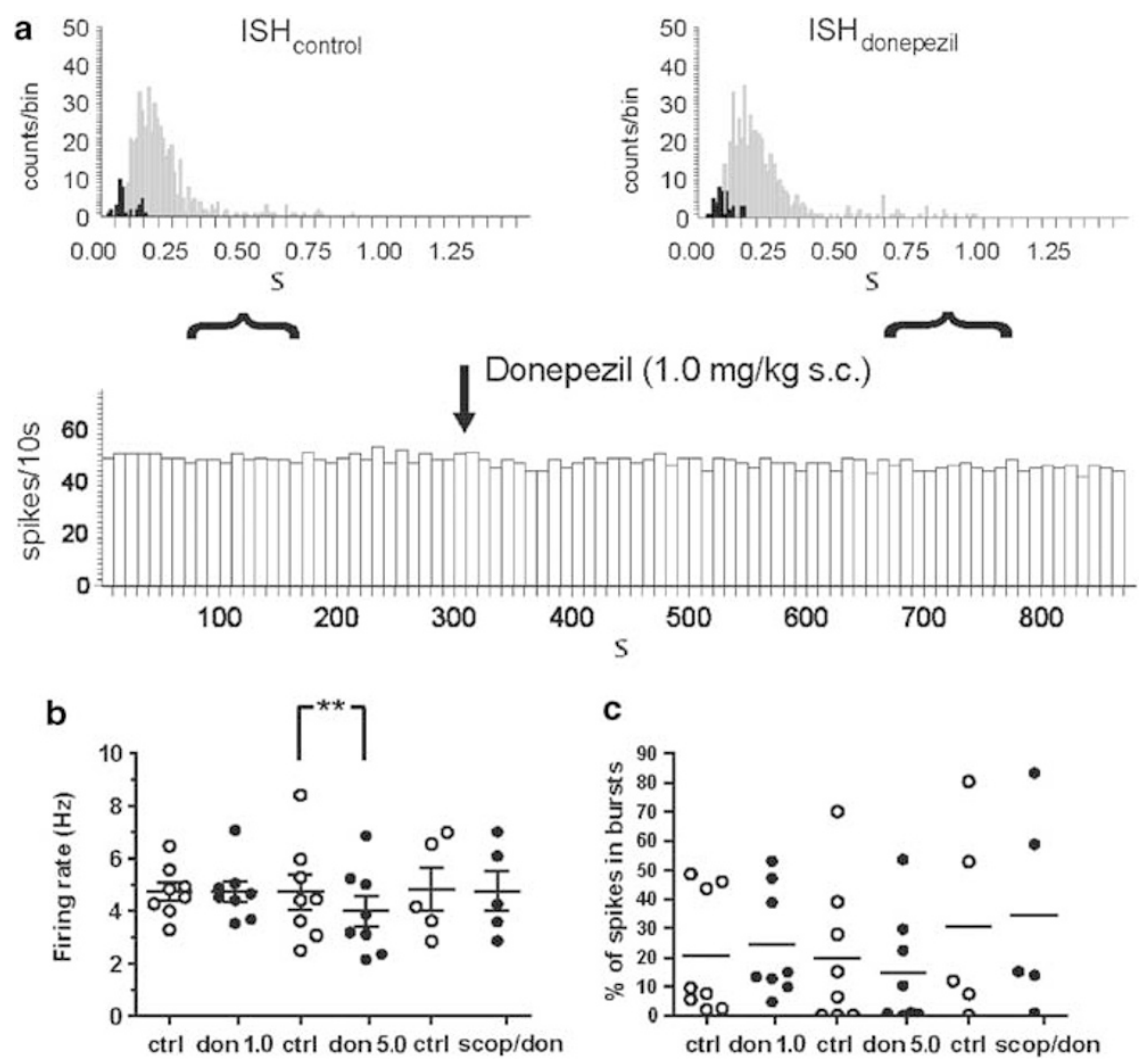

Figure 3 (a) Ratemeter recording and interspike time interval histograms (ISHs) of a representative experiment showing the effects of donepezil ( 1.0 mg/ $\mathrm{kg}$ s.c.) on firing rate and the percentage of spikes fired in bursts (as indicated by black bars in ISHs). Arrow indicates the time of injection. The time periods from which the spike analyses were performed are indicated above the ratemeter recording with lying curly brackets (b) Summary graph showing the effects of $1.0 \mathrm{mg} / \mathrm{kg}, 5.0 \mathrm{mg} / \mathrm{kg}$ of donepezil and $5.0 \mathrm{mg} / \mathrm{kg}$ of donepezil in scopolamine pretreated animals on firing rate. Each cell is represented by an open circle indicating the basal firing rate (ctrl) and a filled circle after donepezil injection. Mean \pm SEM are indicated by horizontal lines. (c) Summary graph showing the effects of $1.0 \mathrm{mg} / \mathrm{kg}, 5.0 \mathrm{mg} / \mathrm{kg}$ of donepezil and $5.0 \mathrm{mg} / \mathrm{kg}$ of donepezil in scopolamine pretreated animals on burst firing. Each cell recorded is represented by an open circle indicating basal burst firing and a filled circle indicating burst firing after donepezil injection. Horizontal line indicates the median. don $=$ donepezil, $\operatorname{scop}=$ scopolamine, ${ }^{*} *=p<0.0$ I.

\section{The Selective AChE Inhibitor Donepezil does not Affect Dopamine Cell Firing}

In order to test whether inhibition of AChE could contribute to the effects of galantamine, we tested the selective AChE inhibitor donepezil at 1.0 and $5.0 \mathrm{mg} / \mathrm{kg}$ (s.c.). Two-way ANOVA of firing rate data revealed no significant differences between the groups, but there was a significant interaction effect $(\mathrm{F} \text { (interaction) })_{1,14}=7.877$, $p<0.05)$. Post hoc analysis revealed that whereas the lower dose had no effect on firing rate $(4.75 \pm 0.35 \mathrm{~Hz}$ before and $4.73 \pm 0.39 \mathrm{~Hz}$ after injection, $p>0.05, n=8$, Figure $3 \mathrm{a}$ and b), the higher dose significantly decreased firing rate $(4.73 \pm 0.66 \mathrm{~Hz}$ before and $3.98 \pm 0.57 \mathrm{~Hz}$ after injection, $p<0.01, n=8$, Figure $3 \mathrm{~b}$ ). There were no statistical differences in burst firing between the two groups (MannWhitney $U$-test) and there was no significant effect of either dose on burst firing when compared to basal (median $8.6 \%$ before and $14.6 \%$ after injection of $1.0 \mathrm{mg} / \mathrm{kg}$ donepezil and $10.8 \%$ before and $5.7 \%$ after $5.0 \mathrm{mg} / \mathrm{kg}, p>0.05, n=8$, Wilcoxon's matched pairs signed ranks test, Figure 3c). Since a higher dose of donepezil had an inhibitory effect on dopamine cell firing, these results argue in favor of the notion that galantamine increases dopamine cell firing through allosteric potentiation of nAChRs. As a conse- quence, the inhibitory effect of donepezil may rather be mediated by mAChRs and therefore we tested the effect of donepezil in the presence of scopolamine. Two-way ANOVA of firing rate (scopolamine alone, donepezil $5.0 \mathrm{mg} / \mathrm{kg}$ alone, and scopolamine + donepezil groups included) revealed no significant treatment effect, but significant time and interaction effects ( $\mathrm{F}$ (interaction) $)_{2}$, $\left.{ }_{17}=4.393, \quad p<0.05\right)$. Newman-Keuls test for multiple comparisons revealed that donepezil did not decrease firing rate significantly in scopolamine-pretreated rats $(4.84 \pm 0.82$ before and $4.77 \pm 0.78$ after donepezil injection, Figure $3 \mathrm{~b}$ ). As presented above, neither scopolamine nor donepezil had significant effects on burst firing and there was no significant effect on burst firing when the two were combined ( $p>0.05$, Figure $3 c)$.

\section{The Effects of Galantamine on Dopamine Cell Firing are Prevented by an $\alpha 7$ nAChR Antagonist and an NMDA Receptor Antagonist, Respectively}

We have recently shown that $\alpha 7 \mathrm{nAChRs}$ within the VTA are critically involved in nicotine-induced burst firing (Schilström et al, 2003). Previous data demonstrate that presynaptic $\alpha 7$-containing nAChR in the VTA can enhance glutamate release and activate NMDA receptors on 

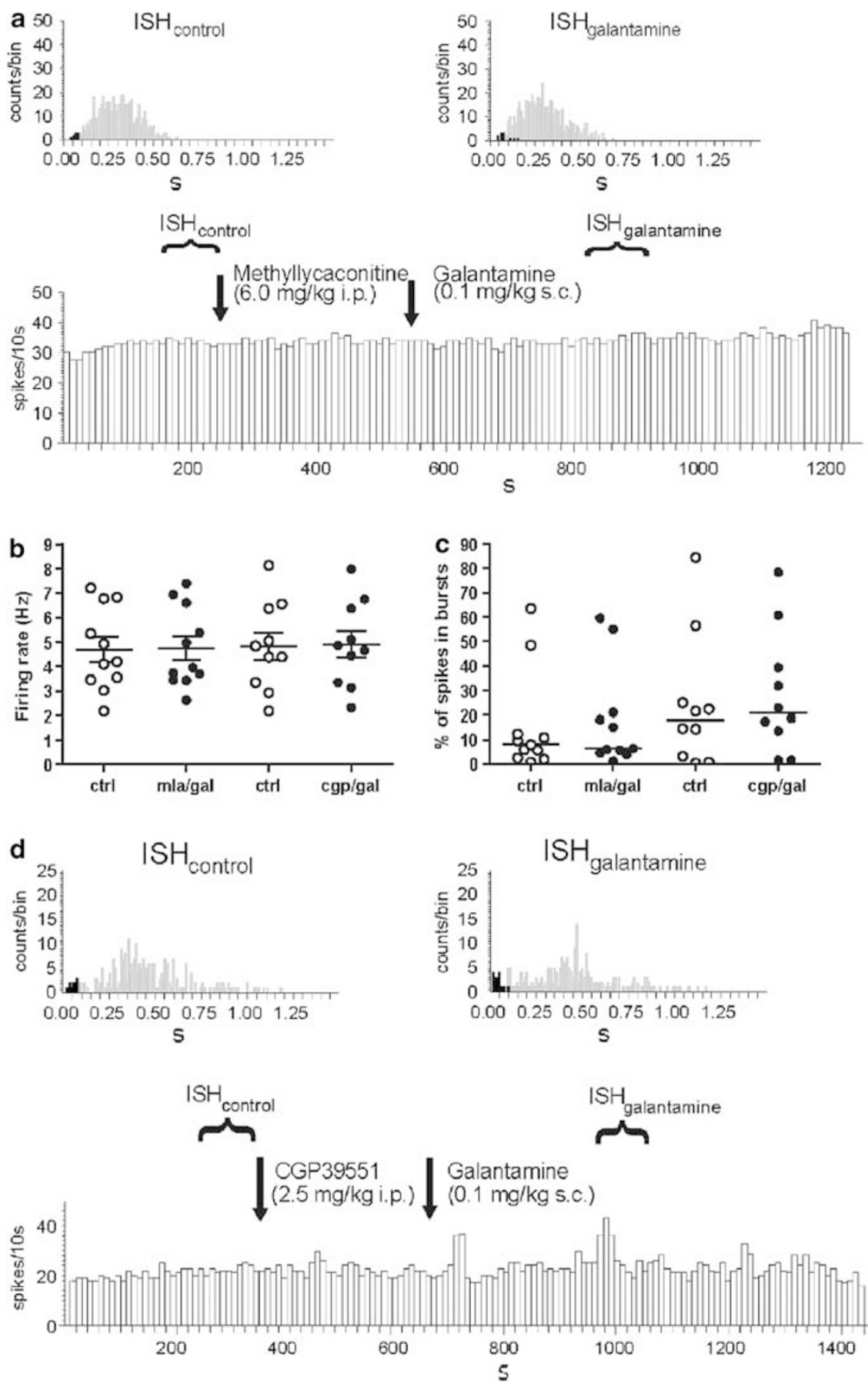

Figure 4 Ratemeter recordings and ISHs showing the effects of galantamine in (a) the presence of the $\alpha 7$ selective nAChR antagonist methyllycaconitine $(6.0 \mathrm{mg} / \mathrm{kg}$ s.c.) and (d) the presence of the competitive NMDA receptor antagonist CGP3955 I (CGP). Arrows indicate the time of injection and the time periods from which the spike analyses were performed are indicated above the ratemeter recording with lying curly brackets. Effects of galantamine on firing rate in methyllycaconitine and CGP3955 I pre-treated animals are summarized in (b) in which the basal level (ctrl) for each cell is represented by an open circle and a filled circle after galantamine injection. Mean \pm SEM are indicated by horizontal lines. (c) Summary graph showing the effects on burst firing. Basal burst firing for each cell (ctrl) is indicated by an open circle and the effect of galantamine by a filled circle. Horizontal line indicates the median. $\mathrm{gal}=$ galantamine, $\mathrm{mla}=$ methyllycaconitine, $\mathrm{cgp}=\mathrm{CGP3955} \mathrm{I}$

dopamine cells (Mansvelder and McGehee, 2000; Schilström et al, 1998a, b, 2000). Therefore, in order to test the involvement of putative $\alpha 7 \mathrm{nAChRs}$ and NMDA receptors, the effect of galantamine was tested in animals pretreated with the $\alpha 7$ nAChR antagonist methyllycaconitine (MLA, $6.0 \mathrm{mg} / \mathrm{kg}$ i.p.) or the NMDA receptor antagonist CGP39551
$(2.5 \mathrm{mg} / \mathrm{kg}$ s.c.), respectively. Here, in accordance with our and others previous results (Schilström et al, 2003; Schwieler et al, 2004), we observed that although MLA had variable effects in individual cells there were no overall significant effects on firing rate $(4.94 \pm 0.58 \mathrm{~Hz}$ before and $4.78 \pm 0.60 \mathrm{~Hz}$ after MLA, $p>0.05$, paired $t$-test, $n=10$, data 

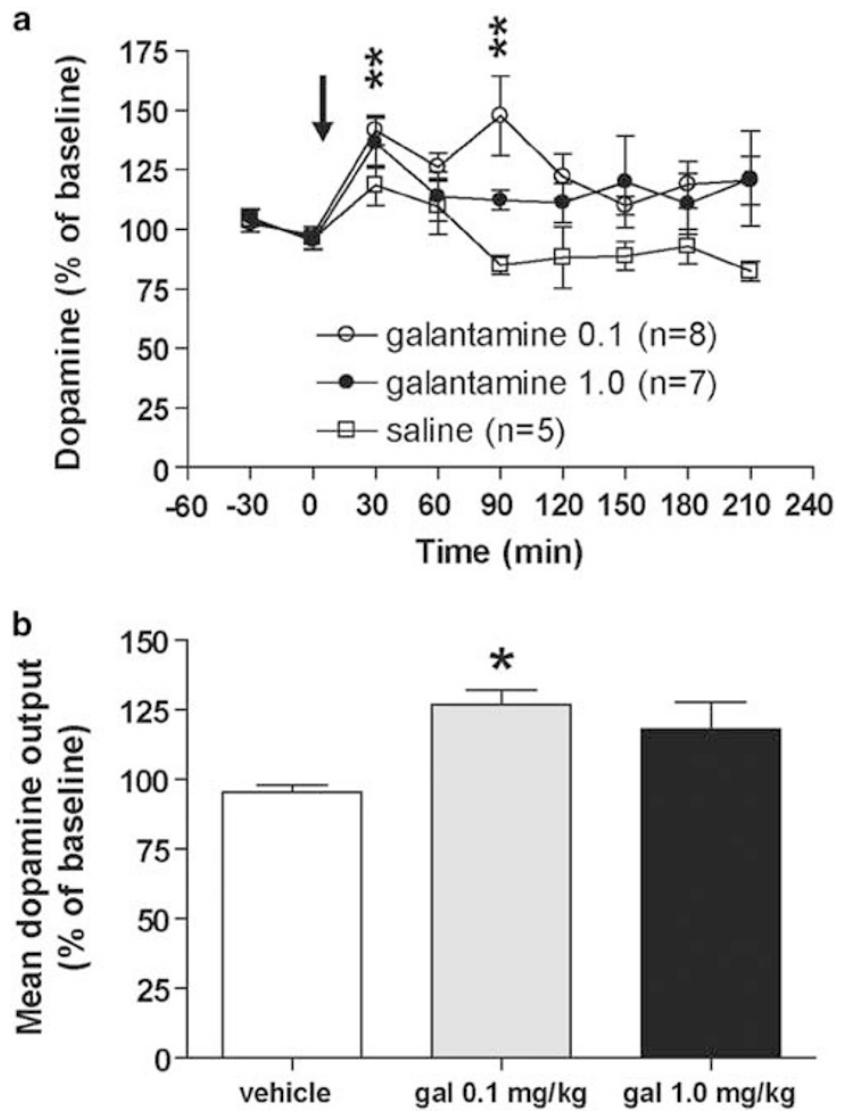

Figure 5 Effects of galantamine on extracellular levels of dopamine in the medial prefrontal cortex. (a) Temporal effects of $0.1 \mathrm{mg} / \mathrm{kg}$ and $1.0 \mathrm{mg} /$ $\mathrm{kg}$ galantamine compared to a vehicle injection on extracellular levels of dopamine in the medial prefrontal cortex. Data are expressed as per cent of baseline and presented as mean \pm SEM. ${ }^{*} *=p<0.01$ compared to baseline. (b) Mean dopamine output during the whole 3.5 hours following injection of vehicle, galantamine $0.1 \mathrm{mg} / \mathrm{kg}$ and galantamine $1.0 \mathrm{mg} / \mathrm{kg}$, respectively. $*=p<0.05$ compared with vehicle.

not shown) or burst firing (median before $25.5 \%$ and median after MLA $35.1 \%, p>0.05$, Wilcoxon's matched pairs signed ranks test, $n=10$, data not shown). In MLApretreated animals, galantamine had no significant effect on firing rate $(4.69 \pm 0.51 \mathrm{~Hz}$ before and $4.75 \pm 0.49 \mathrm{~Hz}$ after galantamine injection, $p>0.05, n=11$, Figure $4 \mathrm{a}$ and $\mathrm{b}$ ) or burst firing (basal value $8.0 \%$ post-galantamine injection $6.4 \%, p>0.05, n=11$, Figure $4 \mathrm{a}$ and $\mathrm{c}$ ).

CGP39551 $(2.5 \mathrm{mg} / \mathrm{kg}$ i.p. $)$ by itself had no significant effects on firing rate (basal $5.62 \pm 0.52 \mathrm{~Hz}$ before and $5.57 \pm 0.73$ after CGP39551, $p>0.05, n=9$, paired $t$-test, data not shown) or burst firing (from basal value of $22-34.1 \%$ postinjection, $p>0.05, n=9$, data not shown). Although the overall effect of CGP39551 on burst firing was nonsignificant, CGP39551 produced rather large effects in individual cells. When galantamine was tested in CGP39551-pretreated animals, there were no dramatic effects on firing rate or burst firing. Basal firing rate was $4.82 \pm 0.57 \mathrm{~Hz}$ and after galantamine injection $4.90 \pm 0.55 \mathrm{~Hz}$ ( $p>0.05, n=10$, Newman-Keul's test for multiple comparisons, Figure $4 \mathrm{~b}$ and d). Median burst firing was $18.1 \%$ under basal conditions and $20.8 \%$ after galantamine injection ( $p>0.05, n=10$, Wilcoxon's matched pairs signed ranks test, Figure $4 \mathrm{c}$ and $d)$.
Galantamine Increases Extracellular Levels of Dopamine in the Prefrontal Cortex

The effects of galantamine $0.1 \mathrm{mg} / \mathrm{kg}$ (s.c.) and $1.0 \mathrm{mg} / \mathrm{kg}$ (s.c.) on dopamine output in the prefrontal cortex were compared to a saline injection. Basal levels of dopamine did not differ between the three different groups $(p>0.05$, one-way ANOVA). The overall basal level of dopamine in the $\mathrm{mPFC}$ was $0.29 \pm 0.03 \mathrm{fmol} / \mathrm{min}$. Statistical analysis (two-way ANOVA) of the data revealed both time $\left(\mathrm{F}(\text { time })_{7,119}=3.825, \quad p<0.001\right)$ and treatment $\left.(\mathrm{F} \text { (treatment })_{2,17}=4.837, p=0.022\right)$ effects, but no interaction effect $\left.(\mathrm{F} \text { (interaction })_{7,119}=1.303, p=0.216\right)$. Further statistical analysis (one-way ANOVA followed by NewmanKeuls test for multiple comparisons) revealed that only the lower dose of galantamine increased dopamine levels in the PFC compared to baseline ( $n=8$, Figure 5a). Galantamine produced a significant elevation of dopamine levels in two different time points after injection $(p<0.01)$, while neither vehicle $(n=5)$ nor the higher dose of galantamine $(n=7)$ produced any significant effects. Analysis of treatment effects (one-way ANOVA followed by Newman-Keuls multiple comparison test) revealed that $0.1 \mathrm{mg} / \mathrm{kg}$, but not $1.0 \mathrm{mg} / \mathrm{kg}$ or saline, increased the mean dopamine output significantly ( $p<0.05$, Figure $5 b)$.

\section{DISCUSSION}

The main findings of the present study are that galantamine increases firing activity of dopaminergic cells in the VTA and, in addition, that galantamine increases dopamine output in vivo in the prefrontal cortex. Our pharmacological analysis strongly suggests that galantamine activates dopamine cell firing through allosteric potentiation of nAChRs. This conclusion is based on the observations herein that the effect of galantamine is not dose dependent, that it is antagonized by the nAChR antagonists mecamylamine, but not the mAChR antagonist scopolamine, and that it is not mimicked by the selective AChE inhibitor donepezil. Our results also propose that the effect of galantamine involves an $\alpha 7 \mathrm{nAChR}$-mediated presynaptic facilitation of glutamate release that activates NMDA receptors, since it was prevented by the $\alpha 7$ nAChR antagonist MLA and the NMDA receptor antagonist CGP39551. In addition, the finding that the effect of galantamine is reversible suggests that, even if $\alpha 7 \mathrm{nAChRs}$ and NMDA receptors are involved, galantamine does not induce plasticity the way nicotine does (Mansvelder and McGehee, 2000).

As mentioned previously (cf. Introduction), emerging clinical data indicate that adjunctive galantamine can improve negative and cognitive symptoms in schizophrenia. We hypothesized that this beneficial effect of galantamine may be due to allosteric potentiation of nAChRs in the VTA, which might generate increased dopamine efflux in the mPFC. Here, galantamine was shown to increase extracellular levels of dopamine in the prefrontal cortex, suggesting that following galantamine administration there is an increased release of dopamine as a result of increased neuronal activity. Galantamine's effect on prefrontal dopamine efflux was significant at $0.1 \mathrm{mg} / \mathrm{kg}$ but not $1.0 \mathrm{mg} / \mathrm{kg}$, an observation that parallels our electrophysiological data 
showing that $0.1 \mathrm{mg} / \mathrm{kg}$ of galantamine increased both firing rate and burst firing of dopaminergic neurons. Thus, it appears that galantamine enhances dopaminergic activity most effectively at a dose that results only in minor AChE inhibition (Geerts et al, 2005), and the effect may therefore rather be due to allosteric potentiation of nAChRs. In support of this conclusion, a recent study reported that a higher dose of galantamine $(3.0 \mathrm{mg} / \mathrm{kg}$ s.c.) did not increase dopamine efflux in the nucleus accumbens (Sharp et al, 2004).

Being an allosteric potentiating ligand, galantamine does not activate nAChRs directly but instead enhances the ability of the endogenous ligand, acetylcholine, to activate the receptor (Schrattenholz et al, 1996; Maelicke et al, 2000). Consequently, since neither of the nAChR antagonists, mecamylamine or MLA, affected firing rate or burst firing when given alone, it appears that even if acetylcholine is available, its concentration may be functionally insufficient under basal conditions to activate nAChRs. Thus, an acetylcholine-mediated activation of $\mathrm{nAChRs}$ may require higher levels of acetylcholine and rather be involved in phasic activations of dopaminergic neurons. In support of this notion, it has been shown that acetylcholine levels in the VTA increase in response to feeding and drinking (Rada et al, 2000). Moreover, electrical or chemical stimulation of the pedunculopontine and laterodorsal tegmental nuclei (PPTg and LdTg), the brainstem nuclei containing acetylcholinergic neurons that send afferents to the VTA, induces burst firing of midbrain dopaminergic cells (Lokwan et al, 1999; Floresco et al, 2003) and increases dopamine release in the nucleus accumbens, in part by activating nAChRs and NMDA receptors in the VTA (Forster and Blaha, 2000). Our data suggest that under conditions of high cholinergic activity, acetylcholine may activate $\alpha 7 \mathrm{nAChRs}$ located on glutamatergic terminals to enhance glutamate release. This mechanism is supported by our previous demonstration that local administration of MLA in the VTA reduces food-induced dopamine release in the nucleus accumbens (Schilström et al, 1998b). Moreover, a recent anatomical study demonstrated that $\alpha 7 \mathrm{nAChRs}$ in the VTA may be located presynaptically at sites indicative of a paracrine mode of signaling (Jones and Wonnacott, 2004).

In contrast to galantamine, donepezil did not activate dopamine cell firing. In fact, the higher dose produced a significant attenuation of firing rate. This finding is surprising since both mAChRs and nAChRs are present on dopaminergic neurons and stimulation of both has been shown to produce excitation (Calabresi et al, 1989; Lacey et al, 1990). The inhibitory effect of donepezil was blocked by the mAChR antagonist scopolamine, indicating that it is mediated by acetylcholine acting at mAChRs. Although most studies have reported excitatory effect of $\mathrm{mAChR}$ activation in the VTA (Lacey et al, 1990; Gronier and Rasmussen, 1998), some reports demonstrate inhibitory effects as well (Fiorillo and Williams, 2000; Zheng and Johnson, 2003). Another possibility could be that inhibition involving mAChRs occurs at the level of the LdTg. Increased levels of acetylcholine due to AChE inhibition in the LdTg might thus activate autoinhibitory mAChRs and, thereby, inhibit the activity of these cells (Luebke et al, 1993; Forster and Blaha, 2000) with a resulting decrease in the release of acetylcholine in the VTA. The fact that following the highest dose of galantamine there was no significant effect on firing rate or prefrontal dopamine output may be related to a similar mechanism. At higher doses, galantamine is indeed an AChE inhibitor and therefore an mAChR-mediated inhibitory effect may counteract the stimulatory effects seen at lower doses. Another, slightly different explanation may be derived from the recent demonstration that donepezil can inhibit nAChR-mediated currents in dopaminergic cells independent of AChE inhibition (Di Angelantonio et al, 2004). Thus, the inhibitory effect mediated by mAChRs could be the result of reduced excitation rather than increased inhibition. Nevertheless, the fact that we observe an inhibitory effect on dopamine cell firing mediated by mAChRs is interesting and remains elusive.

Galantamine was particularly effective at increasing burst firing of dopaminergic cells. It is not known exactly how burst firing may be specifically related to cognitive functions in the prefrontal cortex but since phencyclidine (PCP), a drug that induces a schizophrenia-like syndrome including negative, positive, and cognitive symptoms (Javitt and Zukin, 1991), blocks burst firing of dopaminergic neurons (Svensson, 2000), burst firing is likely to play a critical role. Burst firing is unique in the sense that it results in larger amounts of dopamine release and it induces gene expression in postsynaptic neurons in a dopamine D1 receptor-dependent manner (Gonon and Buda, 1985; Chergui et al, 1996). Burst firing induced by nicotine, which can also enhance cognition (Levin and Simon, 1998), is largely dependent on activation of $\alpha 7$ nAChRs (Schilström et al, 2003), suggesting that galantamine may preferentially modulate $\alpha 7$ nAChRs. Galantamine is known to bind to the $\alpha$-subunit of nAChRs (Schrattenholz et al, 1996) and, obviously, there are more binding sites for galantamine on the homopentameric $\alpha 7$ nAChRs (Couturier et al, 1990) than on the heteropentameric nAChRs which contain only two or three $\alpha$-subunits (Anand et al, 1991; Cooper et al, 1991). This notion is supported by the observation that in HEK-293 cells galantamine appeared to potentiate $\alpha 7 \mathrm{nAChR}$-mediated currents to a greater extent than $\alpha 4 \beta 2 \mathrm{nAChR}$-mediated currents (Maelicke et al, 2001). Thus, galantamine may not only possess the ability to selectively enhance endogenous acetylcholine transmission occurring at nAChRs but may also provide a preference for $\alpha 7$ nAChRs. Importantly, clinical and preclinical data indicate that $\alpha 7 \mathrm{nAChRs}$ are implicated in the pathophysiology of schizophrenia and that $\alpha 7$ agonists may provide a novel treatment alternative (Martin et al, 2004).

Even if our data clearly indicate that allosteric potentiation of nAChRs is the mechanism by which galantamine increases dopamine cell firing, and that $\alpha 7-$ as well as NMDA receptors are implicated, the definite location of the receptors involved remains to be determined. Galantamine was administered systemically and nAChRs in other parts of the brain may be activated and indirectly stimulate dopamine neurons. The notion that galantamine's effect may be mediated by nAChRs located in the VTA is, however, supported by our previous work, showing that the ability of systemic nicotine to enhance nerve terminal dopamine release is specifically antagonized by local administration of $\mathrm{nAChR}$ and $\mathrm{NMDA}$ receptor antagonists into the VTA (Nisell et al, 1994; Schilström et al, 1998a, b). 
In conclusion, we have shown that galantamine, but not donepezil, increases the firing activity of dopaminergic cells in the VTA and, in parallel, enhances terminal dopamine efflux in the prefrontal cortex. This difference between galantamine and donepezil may be related to their reported differential effects in schizophrenia. Galantamine has been shown to improve negative and cognitive symptoms in schizophrenia while donepezil has not (Rosse and Deutsch, 2002; Allen and McEvoy, 2002; Bora et al, 2005; Friedman et al, 2003). As schizophrenia is associated with a very high prevalence of cigarette smoking (Hughes et al, 1986; Ziedonis et al, 1994), a phenomenon that has been suggested to represent an attempted self-medication with nicotine (Hughes et al, 1986; Svensson et al, 1990; Adler et al, 1993), an additional benefit with adjunctive galantamine treatment might be a reduced cigarette smoking in schizophrenia.

\section{ACKNOWLEDGEMENTS}

This study was supported by The Swedish Research Council (grant 4747), the Karolinska Institutet, Janssen-Cilag $A B$, the Lundbeck Foundation, the Magnus Bergvall Foundation, and the Fredrik and Ingrid Thuring Foundation. We thank Mrs Anna Malmerfelt and Mrs Ann-Chatrine Samuelsson for excellent technical assistance.

\section{REFERENCES}

Abi-Dargham A, Mawlawi O, Lombardo I, Gil R, Martinez D, Huang Y et al (2002). Prefrontal dopamine D1 receptors and working memory in schizophrenia. J Neurosci 22: 3708-3719.

Adler LE, Hoffer LD, Wiser A, Freedman R (1993). Normalization of auditory physiology by cigarette smoking in schizophrenic patients. Am J Psychiatry 150: 1856-1861.

Allen TB, McEvoy JP (2002). Galantamine for treatment-resistant schizophrenia. Am J Psychiatry 159: 1244-1245.

Anand R, Conroy WG, Schoepfer R, Whiting P, Lindstrom J (1991). Neuronal nicotinic acetylcholine receptors expressed in Xenopus oocytes have a pentameric quaternary structure. J Biol Chem 266: 11192-11198.

Arnsten AF, Cai JX, Murphy BL, Goldman-Rakic PS (1994). Dopamine D1 receptor mechanisms in the cognitive performance of young adult and aged monkeys. Psychopharmacology 116: $143-151$.

Bora E, Veznedaroğlu B, Kayahan B (2005). The effect of galantamine added to clozapine on cognition of five patients with schizophrenia. Clin Pharmacol 28: 139-141.

Calabresi P, Lacey MG, North RA (1989). Nicotinic excitation of rat ventral tegmental neurones in vitro studied by intracellular recording. Br J Pharmacol 98: 135-140.

Chergui K, Nomikos GG, Mathé JM, Gonon F, Svensson TH (1996). Burst stimulation of the medial forebrain bundle selectively increase Fos-like immunoreactivity in the limbic forebrain of the rat. Neuroscience 72: 141-156.

Cooper E, Couturier S, Ballivet M (1991). Pentameric structure and subunit stoichiometry of a neuronal nicotinic acetylcholine receptor. Nature 350: 235-238.

Couturier S, Bertrand D, Matter J-M, Hernandez M-C, Bertrand S, Millar N et al (1990). A neuronal nicotinic acetylcholine receptor subunit $(\alpha 7)$ is developmentally regulated and forms a homooligomeric channel blocked by $\alpha$-BTX. Neuron 5: $847-856$.

Davies P, Maloney AJF (1976). Selective loss of central cholinergic neurons in Alzheimer's disease. Lancet 2: 1403.
Di Angelantonio S, Bernardi G, Mercuri NB (2004). Donepezil modulates nicotinic receptors of substantia nigra dopaminergic neurones. Br J Pharmacol 141: 644-652.

Egan MF, Goldberg TE, Kolachana BS, Callicott JH, Mazzanti CM, Straub RE et al (2001). Effect of COMT Val108/158 Met genotype on frontal lobe function and risk for schizophrenia. Proc Natl Acad Sci USA 98: 6917-6922.

Fiorillo CD, Williams JT (2000). Cholinergic inhibition of ventral midbrain dopamine neurons. J Neurosci 20: 7855-7860.

Floresco SB, West AR, Ash B, Moore H, Grace AA (2003). Afferent modulation of dopamine neuron firing differentially regulates tonic and phasic dopamine transmission. Nat Neurosci 6: 968-973.

Forster GL, Blaha CD (2000). Laterodorsal tegmental stimulation elicits dopamine efflux in the rat nucleus accumbens by activation of acetylcholine and glutamate receptors in the ventral tegmental area. Eur J Neurosci 12: 3596-3604.

Friedman JI, Adler DN, Howanitz E, Harvey PD, Brenner G, Temporini $\mathrm{H}$ et al (2003). A double blind placebo controlled trial of donepezil adjunctive treatment to risperidone for the cognitive impairment of schizophrenia. Biol Psychiatry 51: 349-357.

Geerts H, Guillaumat P-O, Grantham C, Bode W, Anciaux K, Sachak S (2005). Brain levels and acetylcholineeaterase inhibition with galantamine and donepezil in rats, mice and rabbits. Brain Res 1033: 186-193.

Gonon F, Buda MJ (1985). Regulation of dopamine release by impulse flow and by autoreceptors as studied by in vivo voltammetry in the rat striatum. Neuroscience 14: 765-774.

Grace AA, Bunney BS (1984). The control of firing pattern in nigral dopamine neurons: burst firing. J Neurosci 4: 2877-2890.

Grenhoff J, Aston-Jones G, Svensson TH (1986). Nicotinic effects on the firing pattern of midbrain dopamine neurons. Acta Physiol Scand 128: 351-358.

Gronier B, Rasmussen K (1998). Activation of midbrain presumed dopaminergic neurons by muscarinic cholinergic receptors: an in vivo electrophysiological study in the rat. Br J Pharmacol 124: 455-464.

Hildebrand BE, Nomikos GG, Hertel P, Schilström B, Svensson TH (1998). Reduced dopamine output in the nucleus accumbens but not in the medial prefrontal cortex in rats displaying a mecamylamine-precipitated nicotine withdrawal syndrome. Brain Res 779: 214-225.

Hughes JR, Hatsukami DK, Mitchell JE, Dahlgren LA (1986). Prevalence of smoking among psychiatric outpatients. Am J Psychiatry 143: 993-997.

Ichikawa J, Dai J, O'Laughlin IA, Fowler WL, Meltzer HY (2002). Atypical, but not typical, antipsychotic drugs increase cortical acetylcholine release without an effect in the nucleus accumbens or striatum. Neuropsychopharmacology 26: 325-339.

Javitt DC, Zukin SR (1991). Recent advances in the phencyclidine model of schizophrenia. Am J Psychiatry 148: 1301-1308.

Jones IW, Wonnacott S (2004). Precise localization of $\alpha 7$ nicotinic acetylcoline receptors on glutamatergic axon terminals in the rat ventral tegmental area. J Neurosci 24: 11244-11252.

Lacey MG, Calabresi P, North RA (1990). Muscarine depolarizes rat substantia nigra zona compacta and ventral tegmental neurons in vitro through M1-like receptors. J Pharmacol Exp Ther 253: 395-400.

Levin ED, Simon BB (1998). Nicotinic acetylcholine involvement in cognitive function in animals. Psychopharmacology 138: 217-230.

Lokwan SJ, Overton PG, Berry MS, Clark D (1999). Stimulation of the pedunculopontine nucleus in the rat produces burst firing in A9 dopaminergic neurons. Neuroscience 92: 245-254.

Luebke JI, McCarley RW, Greene RW (1993). Inhibitory action of muscarinic agonists on neurons in the rat laterodorsal tegmental nucleus in vitro. J Neurophysiol 70: 2128-2135. 
Maelicke A, Samochocki M, Jostock R, Fehrenbacher A, Ludwig J, Albuquerque EX et al (2001). Allosteric sensitization of nicotinic receptors by galantamine, a new treatment strategy for Alzheimer's disease. Biol Psychiatry 49: 279-288.

Maelicke A, Schrattenholz A, Samochocki M, Radina M, Albuquerque EX (2000). Allosterically potentiating ligands of nicotinic receptors as a treatment strategy for Alzheimer's disease. Behav Brain Res 113: 199-206.

Mansvelder HD, Keath JR, MGehee DS (2002). Synaptic mechanisms underlie nicotine-induced excitability of brain reward areas. Neuron 14: 905-919.

Mansvelder HD, McGehee DS (2000). Long-term potentiation of excitatory inputs to brain reward areas by nicotine. Neuron 27: 349-357.

Martin LF, Kem WR, Freedman R (2004). Alpha-7 nicotinic agonists: potential new candidates for the treatment of schizophrenia. Psychopharmacology (Berl) 174: 54-64.

Nisell M, Nomikos GG, Svensson TH (1994). Systemic nicotineinduced dopamine release in the rat nucleus accumbens is regulated by nicotinic receptors in the ventral tegmental area. Synapse 16: 36-44.

Paxinos G, Watson C (1998). The Rat Brain in Stereotaxic Coordinates, 4th edn. Academic Press: New York.

Picciotto MR, Zoli M, Rimondini R, Lena C, Marubio LM, Pich EM et al (1998). Acetylcholine receptors containing the beta2 subunit are involved in the reinforcing properties of nicotine. Nature 391: 173-177.

Rada PV, Mark GP, Yeomans JJ, Hoebel BG (2000). Acetylcholine release in the ventral tegmental area by hypothalamic selfstimulation, eating, and drinking. Pharmacol Biochem Behav 65: 375-379.

Rosse RB, Deutsch SI (2002). Adjuvant galantamine administration improves negative symptoms in a patient with treatmentrefractory schizophrenia. Clin Neuropharmacol 25: 272-275.

Schilström B, Fagerquist MV, Zhang X, Hertel P, Panagis G, Nomikos GG et al (2000). Putative role of presynaptic alpha7* nicotinic receptors in nicotine stimulated increases of extracellular levels of glutamate and aspartate in the ventral tegmental area. Synapse 38: 375-383.

Schilström B, Nomikos GG, Nisell M, Hertel P, Svensson TH (1998a). $N$-methyl-D-aspartate receptor antagonism in the ventral tegmental area diminishes the systemic nicotine-induced dopamine release in the nucleus accumbens. Neuroscience 82: 781-789.
Schilström B, Rawal N, Mameli-Engvall M, Nomikos GG, Svensson TH (2003). Dual effects of nicotine on dopamine neurons mediated by different nicotinic receptor subtypes. Int $J$ Neuropsychopharmacol 6: 1-11.

Schilström B, Svensson HM, Svensson TH, Nomikos GG (1998b). Nicotine and food induced dopamine release; putative role of $\alpha 7$ nicotinic receptors. Neuroscience 85: 1005-1009.

Schrattenholz A, Pereira EF, Roth U, Weber KH, Albuquerque EX, Maelicke A (1996). Agonist responses of neuronal nicotinic acetylcholine receptors are potentiated by a novel class of allosterically acting ligands. Mol Pharmacol 49: 1-6.

Schwieler L, Engberg G, Erhardt S (2004). Clozapine modulates midbrain dopamine neuron firing via interaction with the NMDA receptor complex. Synapse 52: 114-122.

Sharp BM, Yatsula M, Fy Y (2004). Effects of galantamine, a nicotinic allosteric potentiating ligand, on nicotine-induced catecholamine release in hippocampus and nucleus accumbens of rats. J Pharmacol Exp Ther 309: 1116-1123.

Svensson TH (2000). Dysfunctional brain dopamine systems induced by psychotomimetic NMDA-receptor antagonists and the effect of antipsychotic drugs. Brain Res Brain Res Rev 31: $320-329$.

Svensson TH (2003). Alpha-adrenoceptor modulation hypothesis of antipsychotic atypicality. Prog Neuropsychopharmacol Biol Psychiatry 27: 1145-1158.

Svensson TH, Grenhoff J, Engberg G (1990). Effect of nicotine on dynamic function of brain catecholaminergic neurons. In: The Biology of Nicotine Dependence (CIBA foundation symposium 152) John Wiley \& Sons Ltd: Chichester. pp 169-185.

Ungless MA, Magill PJ, Bolam JP (2004). Uniform inhibition of dopamine neurons in the ventral tegmental area by aversive stimuli. Science 303: 2040-2042.

Wang RY (1981). Dopaminergic neurons in the rat ventral tegmental area. I. Identification and characterization. Brain Res Rev 3: 123-140.

Zhang L, Zhou F-M, Dani JA (2004). Cholinergic drugs for Alzheimer's disease enhance in vitro dopamine release. Mol Pharmacol 66: 538-544.

Zheng F, Johnson SW (2003). Metabotropic glutamate and muscarinic cholinergic receptor-mediated preferential inhibition of $\mathrm{N}$-methyl-D-aspartate component of transmissions in the ventral tegmental area. Neuroscience 116: 1013-1020.

Ziedonis DM, Kosten TR, Glazer WM, Frances RJ (1994). Nicotine dependence and schizophrenia. Hosp Commun Psychiatry 45: 204-206. 